\title{
The Different Effects on Recognition Memory of Perirhinal Kainate and NMDA Glutamate Receptor Antagonism: Implications for Underlying Plasticity Mechanisms
}

\author{
Gareth R. I. Barker, ${ }^{1 \star}$ E. Clea Warburton, ${ }^{1 \star}$ Timothy Koder, ${ }^{1}$ Nigel P. Dolman, ${ }^{2}$ Julia C. A. More, ${ }^{2}$ John P. Aggleton, ${ }^{3}$ \\ Zafar I. Bashir, ${ }^{1}$ Yves P. Auberson, ${ }^{4}$ David E. Jane, ${ }^{2}$ and Malcolm W. Brown ${ }^{1}$ \\ Medical Research Council Centre for Synaptic Plasticity, Departments of ${ }^{1}$ Anatomy and ${ }^{2}$ Pharmacology, University of Bristol, Bristol BS8 1TD, United \\ Kingdom, ${ }^{3}$ School of Psychology, University of Cardiff, Cardiff CF10 3YG, United Kingdom, and ${ }^{4}$ Novartis Institutes for Biomedical Research, CH-4002 \\ Basel, Switzerland
}

To investigate the involvement of different types of glutamate receptors in recognition memory, selective antagonists of NMDA and kainate receptors were locally infused into the perirhinal cortex of the rat temporal lobe. Such infusion of a selective kainate receptor antagonist produced an unusual pattern of recognition memory impairment: amnesia after a short $(20 \mathrm{~min})$ but not a long $(24 \mathrm{~h})$ delay. In contrast, antagonism of perirhinal NMDA glutamate receptors by locally infused AP-5 (2-amino-5-phosphonopentanoic acid) impaired recognition memory after the long but not the short delay. For both drugs, impairment was found when the drug was present during acquisition but not when it was present during retrieval. Experiments in vitro indicate that selective antagonism of NMDA receptors containing NR2A subunits blocks perirhinal long-term potentiation (LTP), whereas antagonism of NMDA receptors containing NR2B subunits blocks long-term depression (LTD). However, recognition memory after a $24 \mathrm{~h}$ delay was impaired only when both an NR2A and an NR2B antagonist were infused together, not when either was infused separately. These results establish that kainate receptors have a role in recognition memory that is distinct from that of NMDA receptors, that there must be at least two independent underlying memory mechanisms in the infused region, that this region and no other is necessary for both short-term and long-term familiarity discrimination, and that perirhinal-dependent long-term recognition memory does not rely solely on processes used in NMDA-dependent LTP or LTD (although it might be independently supported by components of each type of process with one substituting for the other).

Key words: familiarity discrimination; temporal lobe; LTP/LTD; plasticity; AP-5; NMDA; kainate; recognition memory; perirhinal

\section{Introduction}

The central role of the perirhinal cortex in recognition memory, particularly familiarity discrimination for individual objects, has been established through both ablation and recording studies in monkeys and rats (Brown et al., 1987; Gaffan and Murray, 1992; Fahy et al., 1993; Li et al., 1993; Meunier et al., 1993; Miller et al., 1993; Suzuki et al., 1993; Ennaceur et al., 1996; Ringo, 1996; Suzuki, 1996; Xiang and Brown, 1998; Murray and Bussey, 1999; Brown and Aggleton, 2001). This localization of function makes possible the investigation of the role of specific types of glutamate receptors in this type of memory. In particular, localized bilateral infusion of a muscarinic receptor antagonist into the rat perirhinal cortex has recently been shown to produce an impairment of recognition memory (Warburton et al., 2003), in agreement with

\footnotetext{
Received July 29, 2005; revised Jan. 10, 2006; accepted Jan. 30, 2006

We are grateful to the Medical Research Council for financial support, to J. M. J. Robbins, C. Narduzzo, B. Fry, and

A. Goodall for technical assistance, and to Novartis Pharma AG, Switzerland, for NVP AM077.

G.R.I.B. and E.C.W. contributed equally to this work.

Correspondence should be addressed to Prof. Malcolm W. Brown, Medical Research Council Centre for Synaptic

Plasticity, Department of Anatomy, University of Bristol, Bristol BS8 1TD, UK. E-mail: m.w.brown@bris.ac.uk.

D0I:10.1523/JNEUROSCI.3154-05.2006

Copyright $\odot 2006$ Society for Neuroscience $\quad$ 0270-6474/06/263561-06\$15.00/0
}

findings in the monkey (Tang et al., 1997). This technique establishes that receptor-dependent processes within the perirhinal cortex can be targeted selectively. Notably, it also allows investigation of whether particular glutamate receptor-dependent plastic processes found in the perirhinal cortex may be required for recognition memory. Previous work on the hippocampus using the selective NMDA glutamate receptor antagonist 2-amino-5phosphonopentanoic acid (AP-5) has implicated NMDA receptors in both memory and synaptic plasticity (Collingridge et al., 1983; Morris et al., 1986; Bliss and Collingridge, 1993; Bannerman et al., 1995). Research on the perirhinal cortex has demonstrated that antagonism of its NMDA receptors in vitro blocks the induction of both long-term potentiation (LTP) and long-term depression (LTD) and in vivo impairs recognition memory (Ziakopoulos et al., 1999; Cho et al., 2000; Winters and Bussey, 2005). Recently, the use of more selective antagonists has indicated that perirhinal plasticity demonstrates a particular dependency on subtypes of NMDA receptors (Massey et al., 2004). Thus, selective antagonism of NMDA receptors containing an NR2A subunit blocks the induction of LTP (and depotentiation) but not LTD, whereas selective antagonism of NMDA receptors containing an NR2B subunit blocks LTD but not LTP (or depotentia- 
tion). Accordingly, the use of such subunit-selective antagonism provides a means to investigate whether processes involved in LTP or LTD underlie perirhinal-based recognition memory. Such investigations therefore allow a test of the Bogacz and Brown (2003) computational model of familiarity discrimination, which predicts that the primary synaptic change should be a synaptic weakening such as occurs in LTD.

In contrast to NMDA receptors, the potential cognitive role of kainate glutamate receptors has previously remained unclear because of a lack of selective antagonists or conditional, regionally specific transgenic animals. The availability of a new selective kainate receptor antagonist (of $\mathrm{Glu}_{\mathrm{K} 5}$ subunit-containing receptors) now allows test of the role of these receptors to be made (More et al., 2004) and therefore for this role to be compared with that of NMDA receptors. Accordingly, by using the localized delivery of selective antagonists, here we report the contrasting effects on recognition memory of selective antagonism of NMDA or kainate glutamate receptors in the rat perirhinal cortex and discuss the implications of the findings for the types of plastic processes that may underlie perirhinal-dependent recognition memory.

\section{Materials and Methods}

Subjects. Male pigmented rats (Dark Agouti strain; Bantin and Kingman, Hull, UK), weighing 150-200 g at the start of the experiment, were housed under a $12 \mathrm{~h}$ light/dark cycle. Behavioral training and testing were conducted during the dark phase of the cycle (6:00 A.M. to 6:00 P.M.). All procedures accorded to the United Kingdom Animals Scientific Procedures Act (1986) and associated guidelines and had approval of the University of Bristol Ethical Review Committee.

Cannulation surgery. Each of 30 rats was anesthetized with isoflurane and secured in a stereotaxic frame with the incisor bar set at $3.3 \mathrm{~mm}$ below the interaural line. Two stainless steel guide cannulas (26 gauge; Plastics One, Semat, UK) were implanted through burr holes in the skull at an angle of $20^{\circ}$ to the vertical, using the following coordinates: anteroposterior, $-5.6 \mathrm{~mm}$ from bregma; lateral, $\pm 4.47 \mathrm{~mm}$; vertical, $-6.7 \mathrm{~mm}$ from skull surface. The cannulas were anchored to the skull by two stainless steel screws and dental cement. Between infusions, the cannulas were closed by dummy inserts. After surgery, $>14 \mathrm{~d}$ were allowed for recovery.

Apparatus. Exploration occurred in an open-topped arena $(90 \times 100$ $\mathrm{cm}$ ) with $50 \mathrm{~cm}$ wood walls and a scaffold covered with black cloth to a height of $150 \mathrm{~cm}$, so that no external stimuli could be seen during the experiment. The floor was covered with sawdust. An overhead camera and video recorder were used to monitor and record the animal's behavior for subsequent analysis. The stimuli were triplicate copies of objects made of plastic that varied in shape, color, and size $(10 \times 10 \times 5 \mathrm{~cm}$ to $25 \times 10 \times 5 \mathrm{~cm}$ ) and were too heavy for the animal to displace.

Training. After 1 week of handling, each animal was habituated to the arena without stimuli for $10 \mathrm{~min}$ daily for $4 \mathrm{~d}$ before the commencement of the spontaneous recognition procedure. This procedure comprised an acquisition phase separated by a delay from a recognition test. In the acquisition phase, duplicate copies of an object (e.g., A1 and A2) were placed near the two corners at either end of one side of the arena $(10 \mathrm{~cm}$ from each adjacent wall). The animal was placed into the arena facing the center of the opposite wall and allowed a total of either $40 \mathrm{~s}$ of exploration of A1 and A2 or $4 \mathrm{~min}$ in the arena. Exploratory behavior was defined as the animal directing its nose toward the object at a distance of $<2 \mathrm{~cm}$. Other behaviors such as looking around while sitting on or resting against the object were not considered as exploration. The delay between the phases was $20 \mathrm{~min}$ or $24 \mathrm{~h}$. At test ( 3 min duration), the animal was replaced in the arena and presented with two objects using the same positions as at acquisition: one object (A3) was the third copy of the object used in the sample phase, and the other was a novel object (B3). The positions of the objects in the test and the objects used as novel or familiar were counterbalanced between the animals in a group and between the control and drug-treated groups.

Drug delivery. General procedures followed Warburton et al. (2003).
The drugs used were AP-5 (Tocris Cookson, Ellisville, MO), (S)-1-(2amino-2-carboxyethyl)-3-(2-carboxybenzyl)pyrimidine-2,4-dione (UBP302) (supplied by D.E.J.), $\left(R-\left(R^{\star}, S^{\star}\right)-\alpha\right.$-(4-hydroxyphenyl)- $\beta$ methyl-4-(phenylmethyl)-1-piperidine propanol (Ro 25-6981) (SigmaAldrich, Poole, UK), and (1RS,1S')-[[1-(4-bromo-phenyl)-ethylamino]-(2,3-dioxo-1,2,3,4-tetrahydro-quinoxalin-5-yl)-methyl]phosphonic acid (NVP AAM077) (supplied by Dr. Y. Auberson, Novartis Pharma, Basel, Switzerland). AP-5 was dissolved in sterile $0.9 \%$ saline solution. Other drugs were dissolved initially in $0.1 \mathrm{M} \mathrm{NaOH}$ and $0.9 \%$ saline before further dilution with $0.9 \%$ saline. Control infusions consisted of saline with a concentration of $0.1 \mathrm{M} \mathrm{NaOH}$ equivalent to that of the drug solution. AP-5 was infused at a concentration of $25 \mathrm{~mm}$, UBP302 was infused at a concentration of $1.5 \mathrm{~mm}$, Ro 25-6981 was infused at a concentration of $30 \mu \mathrm{M}$, and NVP AAM077 was infused at a concentration of $10 \mu \mathrm{M}$. Infusions were made into the perirhinal cortex through a 33 gauge cannula (Plastics One) inserted into the implanted cannula and attached to a $5 \mu \mathrm{l}$ Hamilton syringe via polyethylene tubing. A volume of $1.0 \mu \mathrm{l}$ was injected into each hemisphere over a $2 \mathrm{~min}$ period by infusion pump (Harvard Bioscience, Holliston, MA). The infusion cannula remained in place for an additional $5 \mathrm{~min}$.

Design. A different group of rats was used to test the effects of each of the compounds, with two groups being used for AP-5 (one for the acquisition and one for the consolidation and retrieval experiments). The animals were tested after a $20 \mathrm{~min}$ or $24 \mathrm{~h}$ delay. Where both delays were tested for a given drug, the same animals were used with a $7 \mathrm{~d}$ rest between experiments. Two designs were used. (1) To examine whether NMDA or kainate receptors were involved in the acquisition stage of memory, the appropriate antagonist or vehicle was infused starting 15 min before the commencement of the acquisition phase. After $7 \mathrm{~d}$, the other substance (vehicle or antagonist in a crossover design) was infused, and the animal was tested again. (2) To study whether NMDA (or kainate) receptors were involved in retrieval or consolidation, the injection was given $2 \mathrm{~min}$ after the acquisition phase. Again, testing after injection of the other substance followed $7 \mathrm{~d}$ later. The group sizes $(n)$ were as follows: AP- 5 experiments, $n=7$ for testing acquisition and $n=8$ for testing retrieval or consolidation; UBP302 experiments, $n=7$; NVP AAM077 and Ro 25-6981, $n=8$. Data were analyzed only from animals that completed all phases of an experiment with patent, correctly placed cannulas.

Statistical analysis. All measures of exploration were made with the experimenter blind as to the treatment. The discrimination ratio (DR) was calculated as the difference in time spent by each animal exploring the novel compared with the familiar object divided by the total time spent exploring both objects. Comparisons for the vehicle- and drugtreated groups used an ANOVA with repeated measures with time as a between-subjects factor and treatment (drug or vehicle) as a withinsubjects factor. One-sample $t$ tests were used to determine the significance of the DR (compared with zero discrimination) for each group. All tests used a significance level of $p=0.05$ and were two-tailed.

Histology. At the end of the experiment, each rat was anesthetized with Euthetal and perfused transcardially with PBS, followed by $4 \%$ paraformaldehyde. The brain was postfixed in paraformaldehyde for a minimum of $2 \mathrm{~h}$ before being transferred to $30 \%$ sucrose in $0.2 \mathrm{M}$ phosphate buffer and left overnight. Coronal sections were cut at $50 \mu \mathrm{m}$ on a cryostat and stained with cresyl violet. Cannula locations were checked against standardized sections of the rat brain. Histological examination confirmed that infusions were made into the perirhinal cortex (Shi and Cassell, 1999) in all cases. From unpublished observations in the laboratory, using Indian ink and biotinylated oligonucleotides for visualization, the region infused is estimated to be $1-1.5 \mathrm{~mm}^{3}$, with the region being primarily confined to the perirhinal cortex. This spread is consistent with previously quoted results in other brain regions (Martin, 1991; Izquierdo et al., 2000; Attwell et al., 2001).

\section{Results}

The selective kainate $\left(\mathrm{GLU}_{\mathrm{K} 5}\right)$ receptor antagonist UBP302 (1.5 $\mathrm{mm}$ ) was infused locally into a rat's perirhinal cortex via bilaterally implanted cannulas (Warburton et al., 2003) (Fig. 1). Recognition memory was measured by the preferential exploration of a 


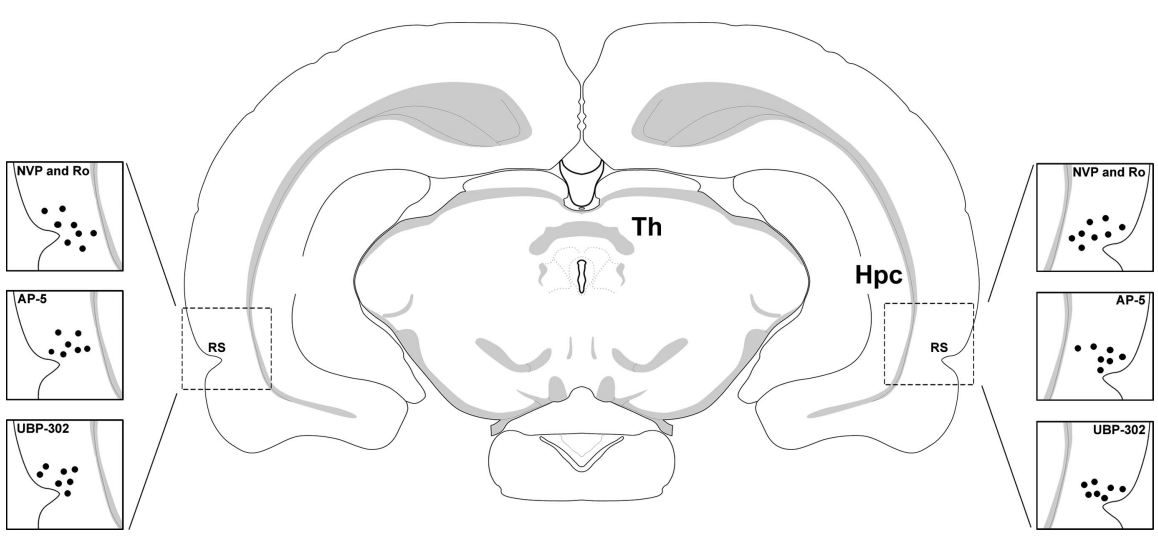

Figure 1. Infusion sites. The sites within the perirhinal cortex at which AP-5, UBP302, NVPAAM077 (NVP), and Ro 25-6981 (Ro) were infused are shown in the boxes expanded from a schematic brain section. Hpc, Hippocampus; RS, rhinal sulcus; Th, thalamus.

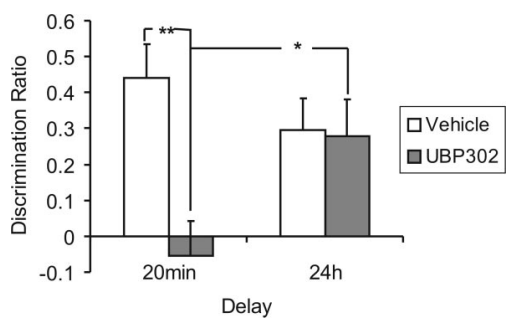

Figure 2. Perirhinal infusion of UBP302 impairs shorter-term (20 min) but not longer-term (24 h) recognition memory. Illustrated for each group is the mean (+SEM) DR (proportion of additional time spent exploring a novel rather than a familiar object). At both $20 \mathrm{~min}$ and $24 \mathrm{~h}$, the DR was significantly different from zero (no discrimination between novel and familiar) for rats infused with vehicle (DR $>0: t_{(6)}=4.3, p<0.01$ and $t_{(6)}=2.9, p<0.05$, respectively). In contrast, for rats infused with UBP302, the DR was not significant from zero at 20 min but was at $24 \mathrm{~h}\left(t_{(6)}=0.5, p>0.1\right.$ and $t_{(6)}=3.1, p<0.05$, respectively). ${ }^{*} p<0.05$ difference between the 20 min and $24 \mathrm{~h}$ delay in the UBP302-treated group; ${ }^{* *} p<0.01$, difference between the vehicle- and UBP302-treated groups at the 20 min delay.

novel rather than a familiar object (Ennaceur and Delacour, 1988), using delays of $20 \mathrm{~min}$ and $24 \mathrm{~h}$. For each delay, UBP302 or vehicle was infused $15 \mathrm{~min}$ before the initial familiarization with an object to investigate the effect of blocking kainate receptors during the familiarization (acquisition). Analysis of exploration behavior at the subsequent test indicated a significant interaction between treatment (drug or vehicle) and delay (ANOVA: $F_{(1,12)}=7.5, p<0.02$ ). Further analysis revealed that for the UBP302 group, recognition memory was impaired compared with vehicle controls after a delay of 20 min (ANOVA: $F_{(1,6)}=20.5, p<0.005$ ) but not when the delay was $24 \mathrm{~h}\left(F_{(1,6)}<1 ; p>0.1\right)$ (Fig. 2). Indeed, the performance of the UBP302-treated group differed significantly at the two time delays $\left(F_{(1,12)}=5.19 ; p<0.05\right)$. Drug infusion $2 \mathrm{~min}$ after acquisition with the test at a 20 min delay did not impair familiarity discrimination, so that UBP302 did not impair consolidation or retrieval mechanisms (Table 1). The drug was without effect on exploration levels (Table 2).

AP-5 (25 mM) or vehicle was infused $15 \mathrm{~min}$ before the initial familiarization with an object to investigate the effect of blocking NMDA receptors during the familiarization (acquisition). Analysis of exploration behavior at subsequent tests at delays of 20 min or $24 \mathrm{~h}$ indicated a significant interaction between treatment and delay (ANOVA: $F_{(1,12)}=6.4, p<0.03$ ). In striking contrast to the effect of UBP302, further analysis revealed that AP-5 impaired recognition memory compared with vehicle controls after a delay of $24 \mathrm{~h}$ (ANOVA: $\left.F_{(1,6)}=10.9, p<0.02\right)$ but not $20 \mathrm{~min}$ $\left(F_{(1,6)}<1 ; p>0.1\right)$ (Fig. 2). The performance of the AP-5-treated group at the two time delays differed significantly $\left(F_{(1,12)}=14.7 ; p<0.005\right)$ (Fig. $3)$. The impairment with the combined drug infusion could not be explained by differences in exploration during the sample or test phases (see Table 2 for details).

To exclude the possibility that the dose level was precisely that required to produce impairment only at the longer delay, when memory might be expected to be weaker, the experiment was repeated using an infusion of $40 \mathrm{~mm}$ AP-5. Again, there was no impairment with a delay of $20 \mathrm{~min}$. Additionally, impairment remained when infusions were made before both acquisition and the test at $24 \mathrm{~h}$, so that statedependent impairment could be excluded: the performance of the vehicle control and AP-5 groups differed significantly (ANOVA: $F_{(1,8)}=16.9, p<$ $0.01)$, with the control group showing significant $\left(t_{(8)}=3.4 ; p<\right.$ 0.01 ) discrimination of the novel over the familiar object, whereas the AP-5 group did not $\left(t_{(8)}=0.7 ; p>0.1\right)$. In an additional experiment, infusion ( 25 mM AP-5) 2 min after acquisition did not impair familiarity discrimination at either $20 \mathrm{~min}$ or 24 h delay, so that AP-5 did not impair consolidation mechanisms; the result at 20 min also established that AP-5 did not impair retrieval (Table 1).

The effects of antagonizing NMDA receptors containing either NR2A or NR2B subunits were investigated by infusing the NR2A-selective antagonist NVP AAM077 (Auberson et al., 2002) or the NR2B-selective antagonist Ro 25-6981 (Fischer et al., 1997). Three experiments were performed in which infusions were made of NVP AAM077 (10 $\mu \mathrm{M})$ or Ro 25-6981 (30 $\mu \mathrm{M})$ or both drugs together. Drug or vehicle infusions were made $15 \mathrm{~min}$ before the initial familiarization with an object, so that either NR2A- or/and NR2B-containing NMDA receptors were blocked during familiarization. Analysis of exploration behavior at subsequent test after a delay of $24 \mathrm{~h}$ indicated a significant interaction between treatment and experiment (ANOVA: $F_{(2,21)}=7.33, p<$ 0.005). In contrast to the effect of AP-5, neither NVP AAM077 nor Ro 25-6981 infused alone impaired preferential exploration relative to vehicle controls at a delay of $24 \mathrm{~h}$ (ANOVAs: $F_{(1,7)}<$ $1.0, p>0.05$ ) (Fig. 4). Memory after a delay of $20 \mathrm{~min}$ was not tested because there was no impairment at this delay with AP-5. However, when NVP AAM077 (10 $\mu \mathrm{M})$ and Ro 25-691 (30 $\mu \mathrm{M})$ were infused together, recognition memory at a $24 \mathrm{~h}$ delay was significantly impaired compared with controls $\left(F_{(1,7)}=16.6 ; p<\right.$ 0.005 ), as found for AP-5 (Fig. 4). The memory differences between the individual and the combined infusions were significant (ANOVA, Bonferroni-corrected comparisons of means) for both NVP AAM077 $(p<0.005)$ and Ro 25-6981 $(p<0.03)$. The impairment with the combined drug infusion could not be explained by differences in exploration during the sample or test phases (Table 2).

\section{Discussion}

The results of local infusions into the perirhinal cortex establish that recognition memory is impaired when kainate receptors are selectively antagonized by UBP302 at a delay of 20 min but not $24 \mathrm{~h}$ and when NMDA receptors are selectively antagonized by AP-5, or by NVP AAM077 and Ro 25-6981 given together, at a delay of $24 \mathrm{~h}$ but not $20 \mathrm{~min}$. The impairment produced by kainate receptor antagonism is unusual because there is short-term 
Table 1. Tests of consolidation and retrieval

\begin{tabular}{lll}
\hline Infusion & 20 min delay & 24h delay \\
\hline UBP302 & $\mathrm{DR}=0.47 \pm 0.12\left(t_{(6)}=3.7 ; p<0.05\right)$ & \\
Vehicle & $\mathrm{DR}=0.38 \pm 0.07\left(t_{(6)}=5.8 ; p<0.001\right)$ & \\
AP-5 & $\mathrm{DR}=0.47 \pm 0.07\left(t_{(7)}=6.4 ; p<0.001\right)$ & $\mathrm{DR}=0.36 \pm 0.05\left(t_{(7)}=6.9 ; p<0.001\right)$ \\
Vehicle & $\mathrm{DR}=0.26 \pm 0.08\left(t_{(7)}=3.2 ; p<0.05\right)$ & $\mathrm{DR}=0.50 \pm 0.05\left(t_{(7)}=9.6 ; p<0.001\right)$ \\
\hline
\end{tabular}

Vehicle or drug was infused $2 \mathrm{~min}$ after the completion of the acquisition test. In each case for each delay tested, the DR was significantly different from zero (one-sample $t$ test), indicating a lack of effect on consolidation or retrieval. There were no differences in exploration at acquisition or test (data not shown).

amnesia, followed by long-term remembrance. The observed impairments were in the acquisition of information because memory was not impaired when infusion of UBP302 or AP- 5 was after acquisition. The impairment at $24 \mathrm{~h}$ produced by AP-5 is in agreement with other recently reported findings (Winters and Bussey, 2005), except that an effect on consolidation as well as acquisition was reported in that study. The studies differ in rat strain, memory delay, and the precise doses used; however, the lack of effect on consolidation in the present experiments is most probably attributable to the slightly longer delay between the start of the familiarization (acquisition) phase and drug infusion in the present study. Accordingly, memory acquisition underlying familiarity discrimination for individual objects is kainate receptor independent at a delay of $24 \mathrm{~h}$, although it is kainate receptor dependent at a delay of $20 \mathrm{~min}$. In contrast, such memory acquisition is NMDA receptor dependent at a delay of $24 \mathrm{~h}$, although it is NMDA receptor independent at a delay of $20 \mathrm{~min}$.

That the amnesia at the short delay is kainate receptor dependent may be accepted with confidence because, at the dose used, UBP302 has negligible agonist or antagonist activity at other common neurotransmitter receptors, including other glutamate and muscarinic cholinergic receptors (More et al., 2004). Thus, UBP302 is the active $S$ enantiomer of UBP296. The racemic mixture (RS)-1-(2-amino-2-carboxyethyl)-3-(2-carboxybenzyl) pyrimidine-2,4-dione (UBP296) is a selective $\mathrm{GLU}_{\mathrm{K} 5}$ receptor antagonist $\left(K_{\mathrm{B}}\right.$ value $\left.0.6 \mu \mathrm{M}\right)$ with no activity on NMDA $(50 \mu \mathrm{M})$ or $\mathrm{GLU}_{\mathrm{K} 6}$ or $\mathrm{GLU}_{\mathrm{K} 2}$ receptors $(100 \mu \mathrm{M})$ (More et al., 2004). UBP302 is a potent antagonist of native $\mathrm{GLU}_{\mathrm{K} 5}$ receptors on spinal dorsal root $\left(K_{\mathrm{D}}\right.$ value $\left.0.4 \mu \mathrm{M}\right)$ with $\sim 260$-fold selectivity versus native AMPA receptors expressed on spinal neurons (More et al., 2004). In recent studies, UBP296 has been shown to have no activity at $300 \mu \mathrm{M}$ on recombinant homomeric human $\mathrm{GLU}_{\mathrm{A} 1-4}$ AMPA receptors and has no agonist or antagonist activity at $100 \mu \mathrm{M}$ when tested on recombinant homomeric human M1-M5 muscarinic cholinergic receptors (A. J. Alt, C. C. Felder, and D. E. Jane, unpublished observations). Thus, one can be confident that UBP302 is $\mathrm{GLU}_{\mathrm{K} 5}$ selective and its effects occur via kainate receptors.

It is theoretically possible that any UBP302-induced impairment at the long delay is masked by memory that is independent of the infused region (e.g., by the formation of another memory trace outside the infused region). However, the existence of such an additional memory trace may be excluded, because when the perirhinal region is infused with AP-5, there is memory impairment at the long delay. Hence, operation of the infused region is essential to recognition memory at the long delay, and no other region can compensate. Indeed, all attempts to explain the results through memory being set up in another region meet the difficulty that the hypothesized additional region has to be necessary for memory at $20 \mathrm{~min}$ but not $24 \mathrm{~h}$ when AP-5 is infused into the perirhinal cortex and for memory at $24 \mathrm{~h}$ but not $20 \mathrm{~min}$ when UBP302 is infused into the perirhinal cortex. Such a situation is implausible. Hence, in particular, the hippocampus fails to provide an alternative memory site. The critical region is likely to be the perirhinal cortex because the infusion is likely to have reached most of the perirhinal cortex (Shi and Cassell, 1999) and, on the basis of work in other areas (Martin, 1991; Izquierdo et al., 2000; Attwell et al., 2001), is unlikely to have affected more than a minor part of either of the adjacent regions of area Te2 or the entorhinal cortex.

It follows that there is more than one recognition memory mechanism operating within the perirhinal and adjacent cortices: an NMDA receptor-dependent mechanism that is responsible for memory at $24 \mathrm{~h}$ and a kainate receptor-dependent mechanism

\section{Table 2. Exploration times}

\begin{tabular}{|c|c|c|c|c|}
\hline Infusion & Delay & Time to complete acquisition phase (s) & Total exploration in acquisition phase (s) & Total exploration in test phase (s) \\
\hline Vehicle & $20 \min (n=7)$ & $240 \pm 0.3$ & $28 \pm 2$ & $18 \pm 2$ \\
\hline UBP302 & & $\begin{array}{l}239 \pm 0.3 \\
\left(F_{(1,6)}<1.0 ; N S\right)\end{array}$ & $\begin{array}{l}31 \pm 2 \\
\left(F_{(1,6)}<1.0 ; \mathrm{NS}\right)\end{array}$ & $\begin{array}{l}20 \pm 1 \\
\left(F_{(1,6)}<1.0 ; \mathrm{NS}\right)\end{array}$ \\
\hline Vehicle & $24 \mathrm{~h}(n=7)$ & $240 \pm 0$ & $27 \pm 2$ & $22 \pm 2$ \\
\hline UBP302 & & $\begin{array}{l}239 \pm 1 \\
\left(F_{(1,6)}<1.0 ; N S\right)\end{array}$ & $\begin{array}{l}33 \pm 1 \\
\left(F_{(1,6)}=4.54 ; N S\right)\end{array}$ & $\begin{array}{l}21 \pm 3 \\
\left(F_{(1,6)}<1.0 ; \mathrm{NS}\right)\end{array}$ \\
\hline Vehicle & $20 \min (n=7)$ & $238 \pm 2$ & $30 \pm 2$ & $23 \pm 3$ \\
\hline AP-5 & & $\begin{array}{l}236 \pm 3 \\
\left(F_{(1,6)}<1.0 ; N S\right)\end{array}$ & $\begin{array}{l}30 \pm 2 \\
\left(F_{(1,6)}<1.0 ; \mathrm{NS}\right)\end{array}$ & $\begin{array}{l}27 \pm 4 \\
\left(F_{(1,6)}<1.0 ; \mathrm{NS}\right)\end{array}$ \\
\hline Vehicle & $24 \mathrm{~h}(n=7)$ & $229 \pm 8$ & $32 \pm 3$ & $27 \pm 1$ \\
\hline AP-5 & & $\begin{array}{l}223 \pm 12 \\
\left(F_{(1,6)}<1.0 ; N S\right)\end{array}$ & $\begin{array}{l}33 \pm 1 \\
\left(F_{(1,6)}<1.0 ; \mathrm{NS}\right)\end{array}$ & $\begin{array}{l}33 \pm 2 \\
\left(F_{(1,6)}=13.4 ; p<0.01\right)\end{array}$ \\
\hline Vehicle & $24 \mathrm{~h}(n=8)$ & $214 \pm 18$ & $34 \pm 2$ & $30 \pm 4$ \\
\hline Ro 25-6981 & & $\begin{array}{l}239 \pm 1 \\
\left(F_{(1,7)}=1.9 ; \mathrm{NS}\right)\end{array}$ & $\begin{array}{l}31 \pm 2 \\
\left(F_{(1,7)}<1.0 ; \mathrm{NS}\right)\end{array}$ & $\begin{array}{l}26 \pm 3 \\
\left(F_{(1,7)}<1.0 ; \mathrm{NS}\right)\end{array}$ \\
\hline Vehicle & $24 \mathrm{~h}(n=8)$ & $237 \pm 3$ & $29 \pm 2$ & $17 \pm 1$ \\
\hline NVP AAM077 & & $\begin{array}{l}233 \pm 7 \\
\left(F_{(1,7)}<1.0 ; N S\right)\end{array}$ & $\begin{array}{l}29 \pm 2 \\
\left(F_{(1,7)}<1.0 ; \mathrm{NS}\right)\end{array}$ & $\begin{array}{l}20 \pm 1 \\
\left(F_{(1,7)}=5.7 ; p=0.05\right)\end{array}$ \\
\hline Vehicle & $24 \mathrm{~h}(n=8)$ & $220 \pm 11$ & $36 \pm 1$ & $20 \pm 3$ \\
\hline Ro 25-6981 plus NVP AAM077 & & $\begin{array}{l}200 \pm 18 \\
\left(F_{(1,7)}=1.1 ; N S\right)\end{array}$ & $\begin{array}{l}35 \pm 3 \\
\left(F_{(1,7)}<1.0 ; \mathrm{NS}\right)\end{array}$ & $\begin{array}{l}26 \pm 2 \\
\left(F_{(1,7)}=2.5 ; \mathrm{NS}\right)\end{array}$ \\
\hline
\end{tabular}




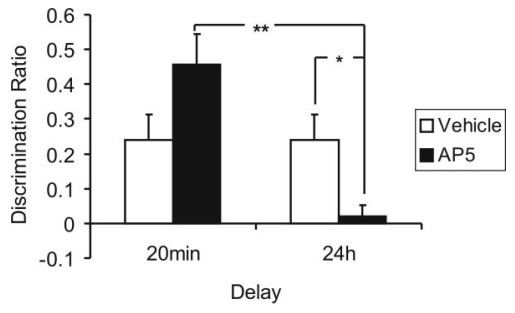

Figure 3. Perirhinal infusion of AP-5 impairs longer-term ( $24 \mathrm{~h}$ ) but not shorter-term (20 $\mathrm{min}$ ) recognition memory. At both $20 \mathrm{~min}$ and $24 \mathrm{~h}$, rats infused with vehicle showed significantly greater mean relative exploration of a novel than a familiar object (DR $>0: t_{(6)}=4.5$, $p<0.01$ and $t_{(6)}=3.6, p<0.05$, respectively). In contrast, for rats infused with AP-5, the difference in exploration was significant at 20 min but not at $24 \mathrm{~h}\left(\mathrm{DR}>0: t_{(6)}=4.8, p<0.01\right.$ and $t_{(6)}=0.3, p>0.1$, respectively). ${ }^{*} p<0.05$, difference between vehicle-and AP-5-treated groups at the $24 \mathrm{~h}$ delay; ${ }^{* *} p<0.01$, difference between the $20 \mathrm{~min}$ and $24 \mathrm{~h}$ delay in the AP-5-treated group.

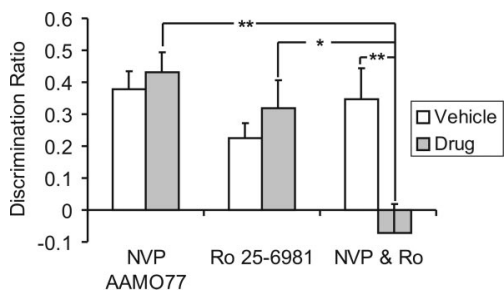

Figure 4. Perirhinal infusion of neither Ro 25-6981, which antagonizes NMDA receptors containing NR2B subunits, nor NVP AAM077, which antagonizes NMDA receptors containing NR2A subunits, impaired longer-term $(24 \mathrm{~h})$ recognition memory. Both vehicle controls and both drug groups significantly discriminated between novel and familiar objects (DR $>0$ : Ro 25-6981: $t_{(7)}=3.0, p<0.05$; controls: $t_{(7)}=4.0, p<0.01$; NVP AAM077: $t_{(7)}=6.4, p<$ 0.001 ; controls: $\left.t_{(7)}=6.1, p<0.001\right)$. There was no significant difference between the groups. In contrast, perirhinal infusion of Ro 25-6981 (Ro) together with NVP AAM077 (NVP) impaired longer-term $(24 \mathrm{~h})$ recognition memory. The vehicle group showed significantly greater mean relative exploration of a novel than a familiar object ( $\left.D R>0: t_{(7)}=3.2, p<0.05\right)$, whereas for the drug group, the difference in exploration was not significant $\left(t_{(7)}=0.7, p>0.1\right) .{ }^{*} p<$ 0.05 , difference between the Ro 25-6981- and the combined NVP AAM077/Ro 25-6981-treated groups; ${ }^{* *} p<0.01$, difference between the vehicle- and combined NVP AAM077/Ro 25-6981treated groups and between the NVP AAM077- and the combined NVP AAM077/Ro 25-6981treated groups.

that is responsible for memory at $20 \mathrm{~min}$. The conclusion that there must be more than one recognition memory mechanism within the perirhinal and adjacent cortices is in accord with the findings of neuronal recording experiments (Fahy et al., 1993; Xiang and Brown, 1998). Indeed, the fast-onset plasticity of the so-called recency and novelty responses compared with the slowonset, long-lasting plasticity of familiarity responses (Xiang and Brown, 1998) provides a potential explanation of the behavioral findings if the fast changes are kainate receptor dependent (supporting memory at the shorter delay) and the slow changes are NMDA receptor dependent (supporting memory at the longer delay).

The present results have major implications for potential underlying plasticity mechanisms. First, the underlying kainatedependent synaptic plastic mechanism is expressed relatively rapidly ( $<20 \mathrm{~min}$ ) but is relatively short lasting because it is insufficient to support memory at the $24 \mathrm{~h}$ delay. Second, the NMDA receptor-dependent plastic process in the perirhinal cortex is long-lasting $(24 \mathrm{~h})$, but the underlying synaptic change must develop slowly, otherwise the NMDA-dependent process should prevent there being amnesia at the short delay. Given this, then a classical, rapidly induced NMDA receptor-dependent LTP-like plastic process, as seen in the hippocampus (Col- lingridge et al., 1983; Bliss and Collingridge, 1993) and perirhinal cortex (Ziakopoulos et al., 1999; Cho et al., 2000), is not essential to perirhinal familiarity discrimination. Such plasticity is marked by rapid induction and expression and therefore should have supported memory at 20 min even when kainate receptors were antagonized, but the results demonstrate that memory was impaired at this delay so that a rapidly induced, NMDA-dependent, LTP-like process cannot underlie such memory. This conclusion is further supported by the finding that scopolamine impairs recognition memory after a delay of $20 \mathrm{~min}$ but does not block the induction of perirhinal LTP (Warburton et al., 2003). In contrast, scopolamine does block the induction of perirhinal LTD (Warburton et al., 2003); however, as discussed below, the findings of the present experiments are not readily consistent with a single LTD-like process underlying familiarity discrimination. Thus, although the results do not disprove the computational model of Bogacz and Brown (2003), they do indicate that it is likely to represent an oversimplification (but see Bogacz et al., 2001).

Further implications concerning potential underlying plasticity mechanisms arise from the findings using subunit-specific NMDA receptor antagonists. At a long delay (24 h), familiarity discrimination was not impaired by antagonism of either NR2A subunit-containing or NR2B subunit-containing NMDA receptors on their own. The selectivity of the two antagonists used (NVP AAM077 and Ro 25-6981) has been established in vitro (Fischer et al., 1997; Auberson et al., 2002); in particular, within slices of the adult rat perirhinal cortex, their effects on LTP (and depotentiation) and LTD are unequivocally differentiable (Massey et al., 2004). Similarly, the behavioral effects after recognition memory were clear cut: there was no evidence of even minor impairment when either drug was given separately, whereas there was no sign of discrimination when both were given together (using the same doses as when they were given separately). Taking the in vivo and in vitro results together, it follows that blockade of the induction of neither LTP/depotentiation nor LTD on its own prevents the formation of long-term recognition memory. Either an NR2A- or an NR2B-dependent process is sufficient to support recognition memory; both have to be blocked (as with AP-5 or both NVP AAM077 and Ro 25-6981 delivered together) to cause impairment. Therefore, if there is a single memory mechanism underlying long-term $(24 \mathrm{~h})$ perirhinal recognition memory, it can use compensatory components from either of two processes (as found in LTP/depotentiation or LTD). Such compensatory mechanisms might involve different means of raising intracellular calcium concentrations or convergence within other intracellular signaling mechanisms. Alternatively, there must be two independent mechanisms underlying such long-term recognition memory, one dependent on a process used in LTP/depotentiation and another dependent on a process used in LTD, either being capable of supporting familiarity discrimination at long delays. If this second alternative is correct, then there are components of at least three plastic mechanisms underlying perirhinal recognition memory: one that is kainate receptor dependent, supporting memory at short delays, and two that are NMDA receptor dependent, supporting memory at long delays. This conclusion indicates that memories may potentially be supported by more than one plastic mechanism. If the complexity of the situation in the perirhinal cortex is mirrored elsewhere, extra care will be needed for firm links to be established between artificially induced plastic processes such as LTP and mechanisms underlying learning. In particular, especially where results seem negative, consideration will need to be given to the potential 
involvement of multiple, possibly compensatory, plastic processes underlying learning.

\section{References}

Attwell PJ, Rahman S, Yeo CH (2001) Acquisition of eyeblink conditioning is critically dependent on normal function in cerebellar cortical lobule HVI. J Neurosci 21:5715-5722.

Auberson YP, Allgeier H, Bischoff S, Lingenhoel K, Moretti R, Schmutz M (2002) 5-Phosphonomethylquinoxalinediones as competitive NMDA receptor antagonists with a preference for the human $1 \mathrm{~A} / 2 \mathrm{~A}$, rather than 1A/2B receptor composition. Bioorg Med Chem Lett 1099-1102.

Bannerman DM, Good MA, Butcher SP, Ramsay M, Morris RGM (1995) Distinct components of spatial learning revealed by prior training and NMDA receptor blockade. Nature 378:182-186.

Bliss TVP, Collingridge GL (1993) A synaptic model of memory-longterm potentiation in the hippocampus. Nature 361:31-39.

Bogacz R, Brown MW (2003) Comparison of computational models of familiarity discrimination in the perirhinal cortex. Hippocampus 13:494-524.

Bogacz R, Brown MW, Giraud-Carrier C (2001) Model of co-operation between recency, familiarity and novelty neurons in the perirhinal cortex. Neurocomputing 38:1121-1126.

Brown MW, Aggleton JP (2001) Recognition memory: what are the roles of the perirhinal cortex and hippocampus? Nat Rev Neurosci 2:51-61.

Brown MW, Wilson FAW, Riches IP (1987) Neuronal evidence that inferomedial temporal cortex is more important than hippocampus in certain processes underlying recognition memory. Brain Res 409:158-162.

Cho K, Kemp N, Noel J, Aggleton JP, Brown MW, Bashir ZI (2000) A new form of long-term depression in the perirhinal cortex. Nat Neurosci 3:150-156.

Collingridge GL, Kehl SJ, McLennan H (1983) Excitatory amino acids in synaptic transmission in the Schaffer collateral-commissural pathway of the rat hippocampus. J Physiol (Lond) 334:33-46.

Ennaceur A, Delacour J (1988) A new one-trial test for neurobiological studies of memory in rats. 1: Behavioral data. Behav Brain Res 31:47-59.

Ennaceur A, Neave N, Aggleton JP (1996) Neurotoxic lesions of the perirhinal cortex do not mimic the behavioural effects of fornix transection in the rat. Behav Brain Res 80:9-25.

Fahy FL, Riches IP, Brown MW (1993) Neuronal activity related to visual recognition memory: long-term memory and the encoding of recency and familiarity information in the primate anterior and medial inferior temporal and rhinal cortex. Exp Brain Res 96:457-472.

Fischer G, Mutel V, Trube G, Malherbe P, Kew JNC, Mohasci E, Heitz MP, Kemp JA (1997) Ro-25-6981, a highly potent and selective blocker of $\mathrm{N}$-methyl-D-aspartate receptors containing the NR2B subunit. Characterisation in vitro. J Pharmacol Exp Ther 283:1285-1292.

Gaffan D, Murray EA (1992) Monkeys (Macaca fascicularis) with rhinal cortex ablations succeed in object discrimination learning despite 24-hr intertrial intervals and fail at matching to sample despite double sample presentations. Behav Neurosci 106:30-38.

Izquierdo L, Barros DM, Ardenghi PG, Pereira P, Rodrigues C, Choi $\mathrm{H}$, Medina JH, Izquierdo I (2000) Different hippocampal molecular re- quirements for short- and long-term retrieval of one-trial avoidance learning. Behav Brain Res 111:93-98.

Li L, Miller EK, Desimone R (1993) The representation of stimulus familiarity in anterior inferior temporal cortex. J Neurophysiol 69:1918-1929.

Martin J (1991) Autoradiographic estimation of the extent of reversible inactivation produced by microinjection of lidocaine and muscimol in the rat. Neurosci Lett 127:160-164.

Massey PV, Johnson BE, Moult PR, Auberson YP, Brown MW, Collingridge GL, Bashir ZI (2004) Differential roles of NR2a and NR2b-containing NMDA receptors in cortical long-term potentiation and long-term depression. J Neurosci 24:7821-7828.

Meunier M, Bachevalier J, Mishkin M, Murray EA (1993) Effects on visual recognition of combined and separate ablations of the entorhinal and perirhinal cortex in rhesus monkeys. J Neurosci 13:5418-5432.

Miller EK, Li L, Desimone R (1993) Activity of neurons in anterior inferior temporal cortex during a short-term memory task. J Neurosci 13:1460-1478.

More JCA, Nistico RDNP, Clarke VRJ, Alt AJ, Ogden AM, Buelens FP, Troop HM, Kelland EE, Pilato F, Bleakman D, Bortolotto ZA, Collingridge GL, Jane DE (2004) Characterisation of UBP296; a novel, potent and selective kainate receptor antagonist. Neuropharmacology 47:46-64.

Morris RGM, Anderson E, Lynch GS, Baudry M (1986) Selective impairment of learning and blockade of long-term potentiation by an $\mathrm{N}$-methylD-aspartate receptor antagonist, AP5. Nature 319:774-776.

Murray EA, Bussey TJ (1999) Perceptual-mnemonic functions of the perirhinal cortex. Trends Cogn Neurosci 3:142-151.

Ringo JL (1996) Stimulus specific adaptation in inferior temporal and medial temporal cortex of the monkey. Behav Brain Res 76:191-197.

Shi CJ, Cassell MD (1999) Perirhinal cortex projections to the amygdaloid complex and hippocampal formation in the rat. Comparative Neurology 3406:229-328.

Suzuki WA (1996) The anatomy, physiology and functions of the perirhinal cortex. Curr Opin Neurobiol 6:179-186.

Suzuki WA, Zola-Morgan S, Squire LR, Amaral DG (1993) Lesions of the perirhinal and parahippocampal cortices in the monkey produce longlasting memory impairment in the visual and tactual modalities. J Neurosci 13:2430-2451.

Tang Y, Mishkin M, Aigner TG (1997) Effects of muscarinic blockade in perirhinal cortex during visual recognition. Proc Natl Acad Sci USA 94:12667-12669.

Warburton E, Koder T, Cho K, Massey PV, Duguid G, Barker GRI, Aggleton JP, Bashir ZI, Brown MW (2003) Cholinergic neurotransmission is essential for perirhinal cortical plasticity and recognition memory. Neuron 38:987-996.

Winters BD, Bussey TJ (2005) Glutamate receptors in perirhinal cortex mediate encoding, retrieval, and consolidation of object recognition memory. J Neurosci 25:4243-4251.

Xiang JZ, Brown MW (1998) Differential neuronal encoding of novelty, familiarity and recency in regions of the anterior temporal lobe. Neuropharmacology 37:657-676.

Ziakopoulos Z, Brown MW, Bashir ZI (1999) Input- and layer-dependent synaptic plasticity in the rat perirhinal cortex in vitro. Neuroscience 92:459-472. 